\title{
Perawatan Instrumen Horn di Jurusan Musik FSP ISI Yogyakarta
}

\author{
Wahyudi \\ Program Studi S-1 Seni Musik, Jurusan Musik, FSP ISI Yogyakarta. Telp. 6282322716469
}

\begin{abstract}
This study is focused on the use of Horn and its maintenance at Music Department, The Faculty of Performing Arts, Yogyakarta Indonesian Institute of the Arts. Horn has a complex organological components system. This study utilizes the qualitative approach through an analytical-descriptive method. This study concludes that a well-controlled used of the instrument will contributes to easiness of its maintenance process. The rusts which are stuck on the inside, as well as outside parts of the instrument, can be cleaned by applying chemical liquid as well as traditional ingredients.
\end{abstract}

Keywords: Horn; organology; instrument maintenance.

\begin{abstract}
Abstrak
Penelitian ini memfokuskan pada penggunaan dan perawatan instrumen Horn di Jurusan Musik FSP ISI Yogyakarta. Instrumen Horn memiliki komponen yang komplek terutama pada organologi. Kemudian jenis penelitian menggunakan pendekatan kualitatif dengan metode deskriptis-analisitikal. Hasil penelitian adalah penggunaan instrumen yang terkontrol akan memudahkan dalam perawatan. Membersihkan karat yang menempel pada bagian dalam maupun luar dapat dilakukan dengan bahan kimia dan bahan tradisional.
\end{abstract}

Kata kunci: Horn; organlogi; pemeliharan instrumen.

\section{Pengantar}

Indonesia merupakan negara kepulauan yang memiliki keanekaragaman budaya dan memiliki berbagai suku. Begitu luas negeri ini dan aneka ragam kebudayaannya sehingga kekayaan alam sangat melimpah, diantaranya baik dari hasil pertanian, perkebunan sampai kekayaan laut. Selain Indonesia memiliki keanekaragaman suku yang tersebar diseluruh kepulauan, misalnya, suku Jawa, Sumatera, Dayak yang ada di Kalimantan dan lain sebagainya. Kemudian muncul identitas dan keanekaragaman budaya, kemunculan budaya lokal atau budaya daerah yang mempunyai ciri khas sendiri dan merupakan kekayaan budaya bangsa.
Koentjaraningrat (2000: 179-182) mengatakan bahwa keanekaragaman budaya Indonesia merupakan sebuah kekayaan yang memiliki nilai-nilai yang terkandung di dalamnya. Proses dari cara hidup sebuah masyarakat dalam rangka kehidupan atau tindakan dalam membentuk sistem gagasan, kemudian hasil karya manusia dijadikan milik diri manusia melalui belajar. Keadaan dan kondisi situasi membuat masyarakat belajar untuk menyikapi lingkungan yang ada, termasuk dalam pembentukan dan mempertahankan kebudayaan. Hubungan tersebut erat kaitannya dengan kondisi masyarakat dalam sebuah kebudayaan. Kemudian muncul masing-masing individu dalam masyarakat mempunyai cara tersendiri dalam usaha memberi kontribusi 
dalam mengembangkan dan mempertahankan kebudayaan. Cara dalam mengembangkan dan mempertahankan sebuah budaya yang dilakukan oleh mahasiswa Horn di Jurusan Musik adalah menggali atau mempelajari lebih dalam yang terkandung dalam instrument Horn. Hal-hal yang dilakukan diantaranya mempelajari cara memainkan, sejarah, organologi atau aspekaspek lain.

Hal yang rutin dilakukan dari pemain Horn adalah dimana latihan rutin setiap hari rata-rata 4 jam, agar mendapatkan ketrampilan yang sesuai dengan silabus atau melebihi dari ketentuan yang berlaku dan diharapkan menemukan hal-hal baru dalam teknik maupun skil. Selanjutnya juga membentuk perilaku pengorganisasian bunyi melalui bermain bersama secara kelompok atau latihan gabungan dengan iringan. Kegiatan mahasiswa yang kebanyakan waktu berkutat dengan instrumennya sendiri tentunya memerlukan perhatian khusus terhadap alatnya, yaitu pemeliharaan atau perawatan instrument.

Penggunan dan perawatan erat kaitanya dengan organologi. Menurut Hendarto (2011:25) mengatakan bahwa organologi pada hakekatnya adalah pengetahuan yang mempelajari tentang alat-alat musik, baik dilihat dari bentuk, suara, cara memainkan. Pandangan lain, Soeharto (1992:65-6) organologi dalam istilah musik merupakan ilmu yang mempelajari tentang alat musik atau studi mengenai alat-alat musik. Menurut sejarahnya, alat ini berawal dari tanduk-berburu atau Horn. Peranan bahan logam baru pada abad ke-14, sedangkan pemasangan katup-katup pengatur baru muncul dipertengahan abad ke-19 yang dipakai sampai sekarang. Corno dalam bahasa Italy dan Horn dalam bahasa Inggris merupakan alat tiup logam yang bentuknya melengkunglingkar.

Kontruksi organologi instrument Horn terdiri dari tabung-tabung yang mel- ingkar yang apabila dipanjangkan bisa mencapai kurang lebih dua meter dan pada ujung berupa bel yang menyerupai trumpet. Instrumen Horn mengalami perkembagan yaitu single Horn dan Double Horn. Kemudian untuk single Horn ditengahnya terdapat 3 katup (klep) yang gunanya untuk menghasilkan nada. Nada tersebut apabila posisi kosong atau tanpa menekan katup menghasilkan nada $C$ beserta trisuaranya. Bila menekan katup (klep) secara berturut-turut posisi 2, 1 dan 3 akan mendapatkan nada setengahnya, yaitu B, Bes dan A beserta trisuaranya. Double Horn ditambahkan katup (klep) satu lagi pada bawahnya ini gunannya untuk mempermudah meng-hasilkan nada karena tabung lebih pendek bila dibandingkan dengan single Horn.

Cara memainkannya terdiri dari katup pengatur di tangan kiri sedangkan tangan kanan membantu memperoleh bunyi dengan memasukkan tangan ke dalam corong (bel). Tangan kanan ini berfungsi dalam hal ketepatan pitc, peredam bunyi, warna suara (tone colour) dan merupakan instrument transposisi. Transposisi yang dimaksud adalah apabila bunyi piano pada nada $\mathrm{F}$ maka instrument Horn di nada $\mathrm{C}$ maka disebut Horn in $\mathrm{F}$ atau naik lima dari instrumen in C.

Di sisi lain, seringnya penggunakan instrument akan menimbulkan suatu masalah yang harus segera diatasi. Masalah tersebut biasanya penyimpanan yang kurang tepat, katup macet akibat dari udara lembab dan jarang dikasih pelumas, atau gangguan lain sehingga dalam latihan individu atau bersama kurang maksimal. Hal ini apabila hanya dibiarkan tanpa ada perawatan dan kurangnya perhatian maka akan menimbulkan kerusakan.

Menurut Ngadiyono (2010:1) mengatakan secara umum pemeliharaan merupakan rangkaian pekerjaan, antara lain memperbaiki, membongkar, atau memeriksa mesin secara saksama dan menyeluruh. Jadi memperbaiki, membongkar, atau memeriksa 
mesin dapat didefinisikan sebagai, tindakan untuk mempertahankan atau memulihkan komponen atau mesin kekeadaan ideal agar menjalankan fungsinya sesuai kebutuhan. Secara umum istilah perawatan memiliki arti, antara lain menjaga, mempertahankan dan melindungi. Kemudian menurut Kamus Besar Bahasa Indonesia (2005: 935) mendefinisikan pemeliharaan sebagai proses atau cara terutama alat produksi agar tahan lama dan tetap dalam kondisi yang baik.

Kemudian apabila pengertian diatas diterapkan diinstrumen Horn menurut Pernia (2006: 25-26) dalam makalah workshop Spanish-Indonesia “Wind Instrument Repair and Maintenance Manual" di SMM Yogyakarta adalah salah satu penyebab utama dari kerusakan adalah akibat kurangnya perhatian terhadap cara membersihkan instrument dan mengkontrol kelembaban. Kelembaban menyebabkan reaksi kimia yang disebut oksidasi, yang berupa jamur atau karat pada logam. Organologi instrumen tiup logam memiliki mekanisme yang kompleks dan membutuhkan perawatan khusus. Perawatan tersebut meliputi tempat menaruh instrument bebas dari debu, instrumen disimpan dalam kondisi tertutup rapat dan jauhkan dari jenis hewan atau serangga. Kemudian pemain juga harus memiliki pengetahuan tentang stuktur intrumen sehingga dapat melakukan perawatan atau pemeriksaan instrumen setelah digunakan.

Air liur dari tubuh manusia mengandung asam karbonat. Asam akan lebih cepat masuk pada bagian katup (valve) dan tuning slide akan menimbulkan perekatan dua bagian penggerak, yaitu pada katup (valve) dan slide tuning. Perawatan pembersihan selalu dilakukan untuk menjaga kelembaban yang terjadi. Sebelum disimpan seyogyanya instrument diberi minyak pada katup dan slide untuk menghindari dari kelembaban dan mencegah oksidasi.

Menurut Sukatmi Susantina mantan pembantu dekan II FSP ISI Yogyakarta sekaligus dosen filsafat di Jurusan Musik yang mengetahui seluk beluk atministrasi, baik di Jurusan Musik dan Dekanat. Kurang lebih pada tahun 1983 Jurusan Musik mendapatkan seperangkat instrumen orkestra lengkap dari Jepang. Instrumen tersebut meliputi Kelompok tiup kayu diantaranya Picolo, Flute Oboe, Klarinet dan Bason. Kelompok tiup logam, French Horn, Tumpete, Trombone dan Tuba. Kelompok Perkusi, Timpani, Grancasa, Xilofon, Marimba dan lain-lain. Kemudian kelompok string, Biola, Biola Alto, Cello dan Contrabas. Namun sebelumnya juga pernah dapat bantuan hibah dari Belanda. Kemudian dalam perjalanannya alat-alat tersebut diperlukan untuk pembelajaran dan orkestra ISI Yogyakarta. Setiap wisuda, Dies Natalis dan acara lain selalu menggunakan orkestra dengan memakai alat tersebut. Secara administrasi dan perawatan dikelola oleh Fakultas Seni Pertunjukan dan Jurusan Musik ISI Yogyakarta bekerja sama dengan mahasiswa. Mengapa demikian karena pihak fakultas sebagai administrasi awal kemudian kepengelola jurusan musik yang selanjutkan atau dipinjam mahasiswa.

\section{Pembahasan}

\section{Fungsi dan Kedudukan Horn}

Perawatan khususnya Horn lebih banyak bekerja sama dengan mahasiswa. Hal tersebut dikarenakan pada setiap semester akhir alat dikembalikan ke administrasi perlengkapan kemudian disemester awal dipinjamkan ke mahasiswa. Selain itu pihak institusi juga membantu dalam pengadaan minyak, lap dan alat pembersih mouthpiece. Selain itu juga mendatangkan tenaga mekanik langsung dari Yamaha Jakarta untuk memberi workshop. Workshop tersebut khusus alat Horn, Trumpete, Trombone dan tuba mengenai cara perawatan terutama memeriksa, membongkar dan memperbaiki (Wawancara dengan pendahulu Pembantu Dekan II FSP ISI Yogyakarta, Sukatmi Susantina, pada 18 Juli 2016). 
Menurut Adler, Samuel (1982:312324) instrumen ini bila dilihat dari bahasa yang dikenal juga dengan istilah Corno, bahasa Itali, dan Cor, Perancis, adalah misteri karena istilah French Horn banyak digunakan di Inggris dan Amerika, namun sebagian besar perkembangan konstruksinya justru terjadi di Jerman. Penjelasan lain bahwa dalam penggunaan orkestra, istilah ini berawal sekitar 1710, terutama di Jerman dan Inggris. Horn sering ditandai dengan sebutan Prancis cor de chasse; namun menurut bahasa Italia adalah Corno da caccia. Dalam hal ini yang menjadi pembahasan adalah instrumen "Horn".

Fungsi dari instrumen ini adalah bisa sebagai solo tanpa atau dengan iringan, duet, trio hingga ensemble Horn. Kemudian ensembel yang digabung dengan instrument lain kuintet, octet, orkes tiup sampai ke orkestra. Instrumen tergolong unik karena mempunyai fungsi ganda dalam ansambel. Komposer dalam karyanya sering membuat komposisi Horn sebagai instrumen woodwind dan sebagai instrumen tiup logam. Dalam musik warna suara (timbre) yang mempunyai ciri khas di abad ke 18 menyerukan untuk melambangkan gagasan kepahlawanan atau heroik.

Horn berawal dari tanduk binatang berfungsi untuk berburu atau berperang namun dalam perkembangannya digunakan sebagai sangkakala seperti penyambutan raja bentuknya belum menggunakan klep. Dalam perkembangannya memiliki klep (Single Horn) untuk menghasilkan nada dan mencapai puncaknya menjadi Double Horn (In F dan in Bes).

\section{Organologi Instrumen Horn}

Organologi menurut Libun, Luren: 2002: 657-658) adalah Studi alat musik dapat ditinjau dari segi sejarah, fungsi sosial, desain, dan konstruksi. Organologi mulai menarik perhatian sejak awal abad ke-17 yang memberikan informasi penting pada instrumen. Kemudian diskusi teknis lainnya muncul dalam karya-karya Mersenne (1636) dan Kircher (1650). organologi dan reproduksi sejarah instrumen dapat diperoleh manfaatnya terutama dalam kasus merawat instrumen. Selain memberikan informasi praktis untuk pengguna (pemain) dan pembuat instrumen, organologi juga berusaha untuk menjelaskan secara kompleks tentang perubahan instrument.

Bell merupakan bagian paling ujung berfungsi untuk meletakkan tangan kanan yang dimasukkan didalamnya. Kemudian valve slide (tabung) single Horn in F) 1, 2 dan 3 selain untuk membuang air dan digunakan untuk tuning (stem) ditarik ulur disesuaikan dengan jarak tertentu sehingga mendapatkan tinggi rendah nada yang diinginkan. Kemudian valve slide (tabung) single Horn in Bes) 1 dan 2 juga berfungsi seperti pada valve slide (tabung) single Horn in F) 1, 2 dan 3 diatas, bedanya tabung valve slide in $\mathrm{F}$ lebih panjang dari valve slide in Bes. Little Finger hook untuk meletakkan jari kelingking dan menahan instrumen agar seimbang dalam posisi memainkan. Triger Valve (kunci Bes) adalah penghubung antara single Horn in $\mathrm{F}$ dan double Horn in bes. Triger Valve (kunci in Bes) tersebut berfungsi untuk memudahkan dalam memproduksi nada karena tabung double Horn lebih pendek bila dibandingkan dengan single Horn. Leadpipe Brace adalah tabung yang digunakan untuk meletakkan mouthpiece dan mouthpiece (monstok) berbentuk mangkok yang berfungsi untuk meletakkan ambasir.

Sedangkan valves (kunci) 1, 2, dan 3 berfungsi membedakan nada yang berbeda dengan dibantu dengan nafas dan ambasir. Posisi open (buka) dalam valves in $\mathrm{F}$ bisa menghasilkan nada C, E, G dan Bes. Valve (kunci) 1 apabila ditekan dapat menghasilkan nada Bes, D, F, dan As. Kemudian valves (kunci) 2 turun setengah dari valves 1 yaitu B, Dis, Fis, dan A. Valves (kunci) 3. Sedangkan turun setengah dari valves 2 yaitu $\mathrm{A}$, Cis, E, dan $G$ atau kunci (kunci) 1 dan 2 
digabung. Gabungan valve (kunci) 2 dan 3 dapat menghasilkan nada As, Des dan Cis.

Valve (kunci) Double Horn 1, 2, dan 3 berbeda dengan Valve (kunci) single Horn. Posisi open (buka) dalam double Horn menghasilkan nada F, A, C dan Ees. Valve (kunci) 1 apabila ditekan dapat menghasilkan nada Bes, Es, G. Kunci (key) 2 juga berubah ketika ditekan yaitu B, E, dan valve (kunci) 3 pada nada A dan D. Gabungan valve (kunci) 1 dan 2 dapat menghasilkan nada D, Fis, A dan D dan gabungan kunci 2 dan 3 menghasilkan nada As dan Des. B flat tuning slide (tabung stem) tempat tuning yang ditarik ulur untuk selaras dengan sesuai yang diinginkan. Sedangkan Draw knobs (tombol) berfungsi untuk memudahkan dalam mencopot tabung yang tepat.

\section{Penggunaan Instrumen Horn}

Mahasiswa Horn di Jurusan Musik FSP ISI Yogyakarta pada awal masuk umumnya belum mempunyai instrument, namun sebagian sudah ada yang memiliki alat sendiri. Mahasiswa yang belum memiliki instrument tentunya meminjam dari Jurusan Musik untuk proses pembelajaran. Prosedur peminjaman melalui beberapa tahap dan tahap awal mengisi blangko yang sudah disediakan. Blangko yang harus diisi adalah nama, nomor induk mahsiswa, tanggal peminjaman dan tanggal pengembalian. Kemudian blangko tersebut disetujui oleh dosen mayor instrument dan ketua jurusan dan bila sudah lengkap pihak peralatan mengeluarkan instrument.

Penggunaan instrumen Horn oleh mahasiswa pada umumnya dilakukan setiap waktu kosong yang tidak bersamaan jam kuliah. Latihan tersebut tidak sama disetiap mahasiswa, menyesuaikan jam kuliah. Kegiatan rutin latihan antara jam 14.00-15.00 dilanjutkan jam 15.30-17.30. Kemudian dilanjutkan jam 18.30-20.00 namun jadwal tersebut bisa berubah karena tiap mahasiswa mempunyai tugas dan kepentingan yang berbeda. Kadang mahasiswa mendapatkan bergabung dengan orkestra di Jakarta dan penggunaan latihan antara jam 10.00-15.00 atau jam 16.00-21.00. Namun tidak semua mahasiswa bisa melakukan hal tersebut diatas tergantung dari minat dan kemampuan.

Instrumen Horn digunakan selain untuk perkulihan juga latihan individu yang rata-rata perhari empat sampai lima jam dan latihan tersebut meliputi teknik, etude dan lagu. Tehnik merupakan pendukung dari memainkan lagu yang terdiri dari: tangga nada mayor dan minor, trisuara mayor minor. Kemudian etude menyerupai lagu namun lebih bersifat teknik atau pengembangan dari pola ritme dan mencakup tangga nada, trisuara. Lagu terdiri dari unsur-unsur melodi baik tanpa maupun dengan iringan. Lagu yang memiliki kesulitan tinggi diperlukan pendukung yaitu, dilatih di ulang-ulang atau latihan tangga nada dan etude yang menyerupai lagu tersebut.

\section{Data dan Kondisi Instrumen Horn}

Menurut data daftar barang inventaris milik Negara Jurusan Musik Fakultas Seni Pertunjukan ISI Yogyakarta tahun 2004 untuk instrumen Horn, antara lain: 1) nomor kode barang 0423 jenis barang French Horn merk Lark nomor pabrik M-4033 tahun buatan 1976 jumlah 1 buah tahun perolehan 1985 kelengkapan dokumen no.1012/PT44/ Um.11.08/87 tanggal 1 April 1985 kondisi barang rusak; 2) nomor kode barang 0423 jenis barang French Horn merk Yamaha nomor pabrik YHR 862 tahun buatan 1980 jumlah 2 buah tahun perolehan 1985 kelengkapan dokumen no.1012/PT44/Um.11.08/87 tanggal 1 April 1985 kondisi barang rusak; 3) nomor kode barang 234.0423 jenis barang French Horn merk korno tahun buatan 1991 jumlah 1 buah tahun perolehan 1991 kelengkapan dokumen no.1012/PT44/Um.11.08/87 tanggal 30 Agustus 1991 kondisi barang rusak; 4) nomor kode barang 234.0423 jenis barang French Horn merk King tahun buatan 1991 jumlah 1 buah tahun perolehan 1991 kelengkapan dokumen no.1012/PT44/Um.11. 
08/87 tanggal 30 Agustus 1991 kondisi barang rusak; 5) nomor kode barang 234.0423 jenis barang French Horn merk Holton tahun buatan 1998 jumlah 1 buah tahun perolehan 1998 kelengkapan dokumen no.1012/PT44/ Um.11.08/87 tanggal 9 Januari 1998 kondisi barang baik.

Kemudian data inventaris diserahkan ke perlengkapan jurusan musik pada tanggal 14 Januari 2016. Barang inventaris Jurusan musik (alat laborat/praktikum) perlengkapan pendidikan Fakultas Seni Pertunjukan ISI Yogyakarta sub bidang alat kesenian, nama barang Horn Merk/tipe Yamaha jumlah 5 buah dengan kondisi baik.

\section{Penyimpanan Instrumen Musik di Juru- san Musik}

Penyimpanan instrument musik baik string, tiup kayu, tiup logam dan perkusi terletak di auditorium Jurusan musik sayap barat. Barang-barang tersebut disimpan dalam ruangan dan diletakkan dalam almari namun sebagian diluar. Sebagian besar kondisi instrumen masih layak pakai namun ada beberapa instrumen yang sudah tidak lengkap atau rusak. Seperti nampak pada gambar 2 dan 3 peletakan instrumen terlihat kurang mendapat perhatian, khususnya untuk instrumen Horn dan trombone. Selain itu dalam ruangan tersebut belum dilengkapi dengan pendingin ruangan sehingga menjadi lembab.

\section{Langkah-langkah Membersihkan Horn} Pernia (2006:24-29) menjelaskan bahwa cara membersihkan instrument Horn (tiup logam) menurut prosedur adalah 1) yang dilakukan sebelum mengerjakan menyiapkan sikat, kain yang kering dan lembut, instrument Horn menggunakan minyak khusus sesuai dengan instrument Horn ,yaitu minyak valve oil (menyerupai salep) dan minyak slide grease (minyak untuk tabung), sampo atau sabun dan bak kecil; 2) Cara membersihkan dimulai dari pencopotan slide satu persatu mulai dari valve 1,2 dan 3 dan seterusnya kemudian rotor cup 1,2,3 dan 4 dan ditaruh pada kain; 3) dalam melepas valve, slide maupun rotor harus hati-hati jangan sampai elemen-element tertentu menjadi aus (gores); 4) dibersihkan terlebih dahulu dengan kain kemudian masukkan valve, slide dan rotor dalam bak yang sudah diisi air hangat. Kemudian satu persatu hingga bagian terkecil dibersihkan dengan sampo dan rotor dan valve (tabung) dibersihkan dengan sikat.

Sesudah dibersihkan dimasukkan atau dipindah dalam air biasa dan diangkat diletakkan pada kain. Langkah berikutnya didiamkan sebentar setelah itu dilap dengan kain hingga tidak ada air yang menempel. Kemudian slide dioleskan minyak cork grease (minyak slide) pada slide dan rotor diberi minyak valve satu persatu dan pasang sesuai dengan urutan. Setelah terpasang semua valve, slide dan rotor diuji suara baik valve (kunci) 1,2 dan 3 apabila ada suara yang tidak pas cek satu-persatu kembali kemungkinan ada rotor yang terbalik. Pastikan bahwa valve, slide dan rotor bekerja seperti semula.

Menurut Yunus alumni juga pemain yang menetap di Jakarta setiap benda apabila dibiarkan tanpa perawatan dapat mengalami kerusakan akibat kontaminasi atau penyebab lain. Melalui perawatan yang rutin instrument Horn dan selalu dalam kondisi terkendali akan siap digunakan setiap waktu. Upaya perawatan ini selain meyakinkan barang siap digunakan juga akan memperpanjang umur. Penyebab kerusakan barang yang dibiarkan tanpa dirawat biasanya karena faktor penyimpanan yang tidak benar, sehingga terjadi korosi, macet akibat dari udara yang lembab dan karena keringnya pelumasan. Dalam memperbaiki Horn tidak dapat ditentukan jangka waktu namun lebih melihat kondisi instrumen. Dilihat fungsi dari masing-masing klep masih berjalan baik atau mengalami kemacetan. Apabila kondisi valve (kunci), slide (tabung), dan rotor sudah tidak berfungsi 
dengan baik, maka diperlukan pembersihan. Persiapan untuk perawatan Horn meliputi silver polis, rotary oil, obeng plus, kain lap biasa dan kain lap bersih.

Membersihkan karat yang menempel rotor 1, 2, dan 3 dengan silver polis kemudian diberi rotary oil. Kerusakan instrument yang sifatnya tidak fatal bisa dikerjakan sendiri, misalnya apabila membongkar kunci (key) 1 , 2, dan 3 dikembalikan pada posisi rata, bantalan karet kunci diganti apabila sudah tidak berfungsi. Kemudian kerusakan yang sifat parah (penyok) atau kruk tidak bisa dicopot karena karat dan apabila tabungnya ada yang lepas harus dilas pada ahlinya.

Sedangkan menurut Satya Utama bahan dari kimia Stainless Steel Polish ini berguna untuk membantu membersihkan debu atau karat yang menempel pada logam. Biasanya digunakan sebelum dan sesudah latihan agar tetap nyaman dipakai. Instrumen Horn terbuat dari logam tentunya akan mudah berjamur atau bahkan karat karena penggunaan setiap hari hampir empat sampai lima jam. Maka dari itu akibat seringnya dalam pemakain dan keringat mengandung garam maka memberi minyak pada kontruksi luar ataua rotor agar tidak cepat aus. Hal-hal yang dipersiapkan sebelum membongkar adalah rotor oil, silece gel (anti lembab), silver polis dan lap microviber (lap khusus Horn). Melihat kondisi instrumen semakin banyak karat akan lama untuk merendam dalam air yang dicampur dengan cuka sampai karat benar-benar hilang. Kemudian pada bagian luar jika terbuat dari silver plate membersihkan karat dengan menggunakan pasta gigi atau silver polis dan apabila instrument berbahan laquer bisa menggunakan sanpoly. Cara mengatasi kerusakan yang sifatnya fatal (kena benturan) benda atau yang lain, dengan tenaga ahli karena diperlukan alat khusus dan ditangani secara professional agar kondisi instrument tetap terkendali.

Selain membersihkan dengan bahan kimia peneliti juga mencoba dengan cara tradisioanal yaitu dengan mencampurkan air, jeruk nipis dan cuka. Cara tersebut cukup berhasil dan bisa menghilangkan karat yang menempel pada logam. Penyebab seringnya dalam pemakian tentu semakin banyak karat yang menempel pada valve dan komponen lain sehingga penekan kunci-kunci tidak bisa bergerak. Maka dari itu diperlukan pembersihan dari komponen tersebut cara yang pertama sudah disampaikan oleh Pernia namun belum membuahkan hasil karena karat yang menempel sudah tebal. Kemudian cara yang kedua adalah komponen direndam dengan mencampurkan air, cuka dan jeruk nipis. Proses tersebut memakan waktu kurang lebih 24 jam, setelah melalui proses tersebut ternyata membuahkan hasil. Karatkarat yang menempel khususnya pada valve hilang dan tidak mengurangi (aus) dari komponen asli.

\section{Penutup}

Peneliti menawarkan perawatan instrumen yang dilakukan oleh Yayasan Musik Amadeus Indonesia yang beralamatkan di Ruko Simprug Galeri blok V, Jl. Teuku Nyak Arif No.10, kel. Grogol selatan, Kec. Kebayoran Lama DKI Jakarta 12220 Phone. (021) 7256557 yaitu dengan menggunakan alat Higrometer Thermometer Extech. Menurut Rahman alumnus Jurusan Musik dengan mayor Cello untuk perawatan instrument tiup logam khususnya tiup logam di Yayasan Amadeus diletakkan dalam almari dan menggunakan pengukur kelembaban udara merk Extech. Fungsi Higrometer Thermometer Extech adalah untuk mengukur kelembapan dan suhu udara. Layar atas menunjukkan waktu, tampilan tengah menunjukkan Suhu dan layar bawah menunjukkan kelembaban dalam persen (\%). Bisa digunakan untuk penyimpanan alat fotografi, kamera, lensa, drybox dan lain-lain. Kondisi di Indonesia yang mempunyai dua musim, yaitu musim kemarau dan hujan tentunya suhu udara tidak menentu kadang panas dan kadang dingin. 


\section{Referensi}

Hagler, Chuck. 1999. Band Instrumen repair Course I. USA: Villanova University Press

Hendarto, Sri. 2011. Organologi Dan Akustik I $\mathcal{E}$ II. Bandung: CV. Lubuk Agung.

Koentjaraningrat. 2000. Pengantar Ilmu Antropologi, Jakarta: Penerbit Rineka Cipta

Ely, Mark C dan Deuren, Amy E. Van. 2009. Wind Talk ForBrass. Oxford New York: Oxford University Press, Inc.

Libun, Lauren. 2002. "Organology", dalam Stanley Sadie, ed. The New Grove Dictionary of Music and Musicians, 2nd edition, vol.2. London: Macmillan Publishers Limited

Tim penyusun Kamus et al. 2005. Kamus Besar Bahasa Indonesia. Edisi Ketiga, Jakarta: Balai Pustaka
Miller, Hugh M. 1991. Pengantar Apresiasi Musik, terj. Triyono Bramantyo PS. Yogyakarta: Perpustakaan ISI Yogyakarta.

Rocchetto, Gabriele. 2002. "Horn", dalam Stanley Sadie, ed. The New Grove Dictionary of Music and Musicians, 2nd edition, vol.2.London: Macmillan Publishers Limited.

Sugiyono. 2011. Metode Penelitian Kuantitatif, Kualitatif, Dan RED, Bandung: Alfabeta Bandung.

Adler, Samuel. 1982/ 1989 (Second edition). The Study of Orchestration. New York: W W. Norton.

Soeharto, M. 1992. Kamus Musik. Jakarta: PT Grasindo Anggota IKAPI.

Pernia, Enrique. 2006. Wind Instrument Repair and Maintenance manual. Makalah Workshop di SMM Yogyakarta

Watanabe, Ruth T. 1967. Introduction to Music Research. New Jersey: Prentice-Hall, Inc.

Yatin Ngadiyono. 2010. Pemeliharaan Mekanik Industri, Yogyakarta: Universitas Negeri Yogyakarta 